Editorial

\title{
Grand Challenges - Management of municipal solid waste
}

As stated on the US National Academy of Engineering (NAE) Grand Challenges website, "the challenges facing engineering today are not those of isolated locales, but of the planet as a whole and all the planet's people. Meeting all those challenges must make the world not only a more technologically advanced and connected place, but also a more sustainable, safe, healthy, and joyous - in other words, better - place" (NAE, 2015).

Likewise, the growing solid waste generation rates pose significant health and technical challenges. According to the US Environmental Protection Agency (2015), the US produced 254 million tons of MSW in 2013, although some sources suggest that the amount may be much greater. Globally, it is estimated that 1.3 billion tonnes of MSW were generated in 2010 and that value is projected to increase to 2.5 billion tonnes per year by 2025 (Hoornweg and Bhada-Tat, 2012).

The collection, processing, and disposal of MSW potentially leads to adverse environmental impacts, undesirable land uses, and reduced housing values. Increasing urbanization magnifies these impacts as population densifies and local disposal options (i.e., landfills) become limited. Therefore, a focus on key opportunities, grand challenges, and potential solutions in our field is needed. The attendees of the 8th Intercontinental Landfill Research Symposium held in Crystal River, Florida US, October 2014 gathered to consider the grand challenges in the management of municipal solid waste (MSW); this editorial summarizes our discussion.

\section{Waste collection and transportation}

Despite decades of public outreach to reduce litter, uncollected waste remains a major issue. In fact, significant quantities of litter end up polluting marine environments and gathering in remote gyres. Collection of MSW has become increasingly complex as the need for multiple streams of source separated waste increases. In most cases, greenhouse gas emissions and fuel consumption associated with collection of multiple streams are well offset by the value of the recovered material. Recycling cost recovery is challenged by falling sales revenue due to China's declining economy, depressed oil prices, and the strong US dollar. The growing trend to single stream collection of recyclables, however, has led to larger quantities of recyclables recovered at lower cost, but also to increased contamination of the recovered materials.

\section{Energy and resource recovery}

MSW is increasingly considered to be a commodity that, if managed properly, can provide positive environmental and economic benefits to a community. However, we must recognize that substances are allowed in products that do not pose any health problems to the consumer during the consumption phase, but after consumption these substances may end up in the environment and may possibly pose a threat to human health and the environment. Attaining the goal of a circular economy cannot result in greater impacts to human health and the environment by dispersing substances into the environment during management of MSW. Thus proper management of MSW requires additional thought. Further, the consequences of increased recycling and zero landfilling must be considered. For example, repeated use of many materials in manufacturing is limited because of the degradation of materials (e.g., paper and cotton) or by the concentration of contaminants in products.

Nitrogen is essential for global food generation, but human activities have disrupted the national nitrogen cycle by increasing the amount of fixed nitrogen in the environment. Fixed nitrogen contributes to the greenhouse effect, destroys the ozone layer, and creates smog and acid rain. Nitrogen is approximately $4 \%$ of the solid waste mass; its release as ammonia during biological waste management processes requires subsequent treatment such as nitrification and denitrification which is energy intensive and can lead to the emission of nitrous oxides. The full recovery of nitrogen from waste is inefficient because it is chemically protected and resists leaching or it is concentrated in recalcitrant organic matter during biological treatment and is unavailable for plant growth.

Rare earth elements (REE) and heavy metals may also be recovered from post-consumer products, mining waste, or coal ash. REE are increasingly in short supply which, because of their importance in manufacturing, could significantly impact global economies. Recovery of waste and electronic equipment (WEEs) is challenged by the variability of REE content in waste, the cost of recovery, and technical limitations in recovering REE.

The energy content in MSW can be recovered during thermal conversion processes. Presently, full-scale thermal conversion processes include waste combustion, gasification, and pyrolysis. Thermal processing significantly reduces the mass of waste requiring landfilling and may be more suitable in urban settings with highly concentrated populations by reducing waste transport needs. Plasma arc treatment is another thermal process under investigation, however an external energy source is required. A wet thermal conversion process receiving increasing attention is hydrothermal carbonization (HTC), which, according to small-scale studies, generates energy and carbon-rich solids (often referred to as hydrochar or biochar, depending on future use) that may ultimately be used as a fuel source, for carbon storage, or as an environmental sorbent. This process may also enable the recovery of other resources from the waste, including nutrients and valuable chemicals (e.g., acetic acid).

These processes all produce gaseous, solid, and liquid products that can be used in power generation (HTC, gasification, 
incineration, pyrolysis, plasma arc), chemical synthesis (gasification, HTC), soil amendments (HTC), or environmental treatment (HTC). Alternatively, the energy and resource value of waste can be derived through anaerobic digestion of organic wastes to produce methane which can serve as a fuel or a precursor for high-value chemicals. The viability of the process is impacted by degradation rates, waste characteristics, microbial dynamics, cost, and potential environmental impacts.

\section{Landfilling}

Landfills will continue to play a role as a final sink for residuals from all waste management processes, despite efforts to achieve zero landfilling. Any other path for residuals will result in the dispersion of product contaminants to the environment. Mechanical biological treatment (MBT) has been shown to be effective in reducing the volume of waste disposed of in landfills and likewise avoiding greenhouse gas emissions, but the cost of waste management increases significantly when these processes are used. There is increasing issue with elevated temperatures in deep landfills that lead to structural issues, reduced quality of gas and leachate, and local impacts on air quality. The legacy of decades of landfilling MSW has created many sites that continue to pose environmental and health risks due to the presence of ammonia-nitrogen, dissolved metals, recalcitrant organic matter, and remaining gas potential. In order to protect the environment from leachate and/ or gas migration, modern landfills are designed and constructed with engineered containment systems. To minimize the long-term environmental impact of landfills, methods to reduce the emission potential are needed prior to a breach of the containment system. Suggested approaches to safely reduce or end post-closure care include the introduction of liquid (e.g., flushing, bioreactors) and aeration. Leachate treatment also poses many challenges. Co-treatment of landfill leachate with wastewater is often practiced, however the presence of recalcitrant organic matter that passes through conventional treatment processes must be considered. Emerging contaminants (e.g., pharmaceuticals, personal care products, nanoparticles, fluorinated compounds) are found in leachate due to the vast number of complex consumer products being manufactured that contain these materials and end up in a landfill at the end of their useful life.

\section{Engineered solutions}

These challenges, however, can be dealt with through research and development of engineered solutions which include, among many others, the following: assessment tools (and appropriate input data) to evaluate potentially sustainable solutions (e.g., life cycle analysis and water/carbon footprint analyses), advanced analytical techniques to identify and characterize emerging containment (e.g., nanoparticles, pharmaceuticals, personal care products, and fluorinated compounds) in complex environmental matrices, appropriate and sustainable processes for leachate treatment, subsurface heat management in landfills, improved process emissions monitoring, regulation of organic waste landfilling (i.e., diversion from landfills), volume reduction of unrecoverable waste, more efficient waste collection (e.g., improved design of vehicles, greater use of natural gas and green fuels, underground vacuum waste collection systems), more sustainable management of process residuals (particularly ash and inert material), and reduced or less toxic chemicals for extraction of resources from waste.

\section{Education}

Technical solutions are certainly essential to meeting the waste management challenges described above, however to effectively implement them, the public must be engaged in waste management decisions. Further, citizen scientists can play a role in identifying and studying waste disposal issues. Through wise consumer choices, the public can demand design of products and packaging for maximum resource recovery and safe residual management. Perhaps most importantly, students who will inherit the planet must be adequately educated in solid waste management and prepared to meet these and other global challenges.

\section{References}

Hoornweg, D., Bhada-Tat, P., 2012. What a Waste: A Global Review of Solid Waste Management, vol. 15.

NAE, 2015. Grand Challenges for Engineering: Managing the Nitrogen Cycle Retrieved July 5, 2015, from <http://www.engineeringchallenges.org/ challenges/nitrogen.aspx>.

US Environmental Protection Agency, 2015. Municipal Solid Waste (MSW) in the United States: 2013 Facts and Figures.

\section{Debra Reinhart Stephanie C. Bolyard University of Central Florida, USA E-mail addresses: Debra.Reinhart@ucf.edu (D. Reinhart), Stephanie.Bolyard@ucf.edu (S.C. Bolyard) \\ Nicole Berge University of South Carolina, USA E-mail address: berge@engr.sc.edu}

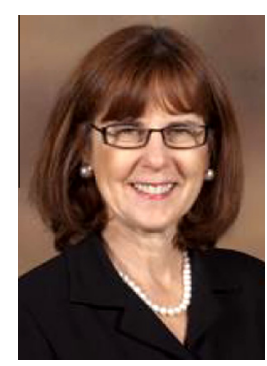

Debra Reinhart is the UCF Assistant Vice President for Research and Commercialization and Pegasus Professor at the University of Central Florida. President of the IWWG, and member of the Environmental Research and Education Foundation board. Registered professional engineer in Florida and Georgia, Fellow of the American Society of Civil Engineers and the American Association for the Advancement of Science.

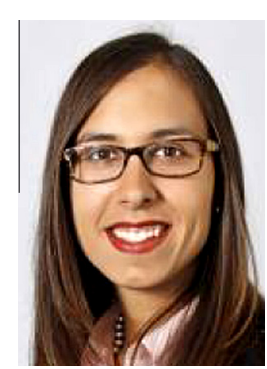

Stephanie C. Bolyard is a Ph.D. candidate at the University of Central Florida. She received her M.S. in Environmental Engineering with a specialization in solid waste management at the University of Central Florida and B.S. in Chemistry from the University of Florida. Her research focuses on sustainable solid waste management, behavior of engineered nanoparticles in landfill leachate, generation, characterization and environmental fate of leachate organic matter.

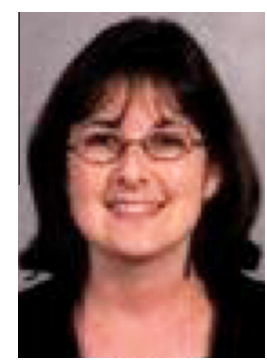

Nicole Berge is an Associate Professor in the Department of Civil and Environmental Engineering at the University of South Carolina. B.S. and M.S. degrees in Civil and Environmental Engineering from the same University, Ph.D. in Environmental Engineering from the University of Central Florida, Postdoctoral Associate at Tufts University. Research activities on sustainable waste treatment techniques and fate/transport of emerging contaminants in waste environments. 